\title{
Sex Education from the Perspective of Elementary School Students, Teachers, and Managers in Northeastern Brazil
}

Maria Lucia Neto de Menezes ${ }^{1}$, Maria das Neves Figueiroa², Waldemar Brandão Neto ${ }^{3}$, Gentil Paiva de Oliveira Júnior ${ }^{4}$, Bruna Layza Gonçalves Lourenço ${ }^{5}$, Thaísa Cristina Xavier Soares de Arruda Falcão ${ }^{5}$, Bárbara Albuquerque Barbosa

\section{Abstract}

Introduction: Sexuality in adolescence is a major focus of interest and concern for parents and educators, thus family and school involvement is imperative for adolescent sex education.

Objectives: This article analyzes teaching scenarios, themes, and difficulties related to sex education, from the perspective of adolescent students, managers, and teachers in Brazilian public schools.

Methods: This is a cross-sectional, exploratory, and descriptive survey, carried out at 5 schools belonging to the $2^{\text {nd }}$ political-administrative region (PAR) in Recife, Pernambuco, Brazil. The sample consisted of 196 individuals (168 teenagers, 19 teachers, and 9 managers) and data was obtained through interviews, conducted in September and October 2017.

Results: The results indicate that the school infrastructure has shortcomings related to: living spaces, teaching scenarios, teacher vocational education, dialogue with families, and interconnection to other educational and health institutions. All this contributes to the persistence of sex education as a theme of biology-based classes.

Conclusion: It is concluded that psychological, cultural, and relational aspects of healthy and safe sexuality persist as knowledge gaps according to the teenagers themselves, and this indicates the need to expand spaces for dialogue and embracement of human diversity within the school environment.
1 Obstetrician nurse. PhD in health of the child and Adolescence. University of Pernambuco (UPE). Recife, PE, Brazil.

2 Nurse. PhD in Molecular Biology. University of Pernambuco (UPE), Recife, PE, Brazil.

3 Nurse. PhD in health of the child and Adolescence, University of Pernambuco (UPE), Recife, PE.

4 Gynecology and Obstetrics Specialist University of Pernambuco (UPE). Recife, PE, Brazil.

5 Undergraduate Nursing student. University of Pernambuco (UPE). Recife, PE, Brazil.

Contact information:

Maria Lucia Neto de Menezes.

Đmaria.luciamenezes@yahoo.com.br

Keywords

Sex Education; Adolescent; Nursing; Health Education. 


\section{Introduction}

Adolescence is marked by deep physical, social, and psychoemotional changes, and this represents one of the most vulnerable periods in the human life cycle [1]. The development of sexuality in adolescence is a major focus of interest and concern for parents and educators, because curiosities and discoveries that take place in this field may be synonyms for pleasure, but also for risks to the life and future plans of teenagers. These risks may be associated with early onset of unprotected sex life, exposure to sexually transmitted diseases (STDs), including acquired immunodeficiency syndrome (AIDS), unplanned pregnancy, among others [2].

The ways of experiencing sexuality, trying out pleasures and desires, rather than the individuals' problems or issues, should be seen as the society and culture's problems or issues. Thus, family and school involvement is imperative in the adolescent sex education process, because this promotes greater clarification about the subject so that young people can experience their sexuality safely, responsibly, and in a healthy way [3].

Children and teenagers carry with them traces of the social context they are inserted in and, for this reason, the school cannot ignore sexuality-related doubts and manifestations, which sometimes are tied to biased ideas, loaded with taboos that can generate violence and distress. Sexuality is the result of a historical construct, produced in the culture, and this may involve instability, multiplicity, and provisionality [4].

Sexuality as a theme brings with it controversies that are usually based on religious beliefs and have little acceptance from parents, who end up hindering the teachers' action when it comes to sex education [5]. The discussion about including sexuality in the Elementary School and High School curriculum has intensified since the 1970s, because this is regarded as key in the education of an individual as a whole.
According to the Brazilian National Curriculum Parameters (PCNs), sex education is regarded as a cross-sectional theme, which should be spread throughout the pedagogical area, which is worked on in all schooling cycles. In order to do so, teachers must be capable to deal with the various contents that address human singularities, so that students can become critical individuals, able to think and discuss the most varied subjects. It is up to the educator, provided with vocational education by the State or a private institution, to promote social and discussion-based actions, aimed at resolving doubts that can generate future problems, including the healthy experience of sexuality [6].

According to the Brazilian Ministry of Education (MEC), the work carried out by the school, named as sexual guidance, should constitute a formal and systematized process that takes place within the facility, which requires planning, so the MEC proposes an intervention by education professionals. Sexuality as a theme must be approached naturally and, because there is a certain difficulty in this regard, initial and continuing education shows to be significant not only for educators in order to talk about the subject, but also for the entire school's pedagogical team [7].

From the health viewpoint, there has been some contradiction between a programmed educational intervention effort in the context of adolescent sexuality and the actual results obtained at the behavior level expressed by teenagers. On the other hand, the increasing degree of permissiveness that characterizes today's society and the lack of authentic and adequate support by parents, teachers, and health professionals have led teenagers to engage in risky behaviors to meet their sexual needs.

Given the above, this study analyzed the teaching scenarios, themes, and difficulties related to sex education at public schools facilities from the perspective of adolescent students, managers, and teachers in Recife, Pernambuco, Brazil. 
This research is relevant because describing pedagogical experiences related to sex education, study scenarios, innovative experiences, and, on the other hand, analyzing difficulties and interests of teachers, students, and managers, may contribute to improve knowledge and pursue pedagogical projects in the areas of sex education and human rights that can promote a responsible and safe sexual experience among teenagers, also capable of assisting teachers in coping with prejudice, discrimination, and violence.

\section{Methods}

This is a cross-sectional, exploratory, and descriptive survey, a research design that enables collecting information directly from people with regard to their ideas, feelings, health status, plans, and beliefs. This study is inserted in a larger research project, entitled "Culture circles: promoting preventive purposes in leprosy with adolescent students".

The research was conducted in Recife, a Northeastern Brazilian capital that covers an area of $219 \mathrm{~km}^{2}(0.2 \%$ of the Pernambuco state's area). Considering the large territorial extension of Recife, we chose to conduct the study within its $2^{\text {nd }}$ political-administrative region (PAR), where the University of Pernambuco (UPE) is located, a Higher Education institution that fulfills a large part of its university outreach and research activities in the health and education fields.

The sample consisted of adolescent students, teachers, and managers from municipal public schools belonging to the $2^{\text {nd }}$ PAR in Recife. The inclusion criteria consisted of these aspects: adolescent students duly enrolled in public schools in Recife, who were attending classes in grades equivalent to 8 and 9 years of school education and aged between 15 and 19 years; and teachers and managers (coordinators, principals, and deputy principals) of the municipal public schools analyzed in this study.
For the purposes of population estimation, we surveyed the total number of teenagers aged between 15 and 19 years and attending classes in grades equivalent to 8 and 9 years of school education -duly enrolled in 2017 in the 5 public facilities providing High School education that belong to the $2^{\text {nd }}$ PAR in Recife-, besides the total number of teachers and managers of each school. Sample calculation was based on a $50 \%$ prevalence estimate, a 95\% confidence interval, and a maximum error of 0.05 . A correction factor of 1.2 was applied and a total of 196 individuals were found by using these parameters.

For sample selection, the following criteria were adopted: 5 teachers from each school (total $=19$ ); 1 principal or deputy principal from each school (total $=6$ ); and 1 coordinator from each school (total $=3$ ). To calculate the number of adolescent interviewees we adopted the proportionality criterion, according to the percentage of students from each school. Thus, 168 teenagers were selected: 34 students from the Municipal School 'Antônio Heráclito Rêgo;' 26 students from the Municipal School 'Mário Melo;' 28 students from the Municipal School 'Olindina Monteiro França;' 64 students from the Municipal School 'Paulo Vl;' and 16 students from the Municipal School 'Jonatas Braga.'

Data collection was conducted in the classrooms in September and October 2017, through face-toface interviews, applying instruments designed by the researchers to managers and teachers in order to deal with description of the teaching scenario (space and physical structure), variables related to the respondent's profile, insertion of sex education as a theme or subject in the school, and curricular contents interconnecting sex education to difficulties for sex education. The interview with adolescent students included variables related to the respondent's profile and social, sexual, and reproductive behavior, as well as the experience of studying themes related to sex education at school. 
For the analysis, a database was built through the software Microsoft Excel, which was exported to the software SPSS, version 18. To describe the profile of students, managers, and teachers, absolute values were calculated and the respective frequency distributions were constructed. Then, the confidence intervals were calculated for the percentages and the chi-square test was applied for proportion comparison. In order to compare the profile of male and female students, contingency tables were constructed and the chi-square test was applied. In cases where the assumptions of the chi-square test were not confirmed, the Fisher's exact test was applied. All conclusions were drawn considering a 5\% significance level.

The research complied with the standards of Resolution No. 466/2012, from the Brazilian National Health Council (CNS), concerning the ethical aspects of research involving human beings. The project was registered under the Brazilian Certificate of Submission for Ethical Assessment (CAAE) No. 74867317.9.0000.5192 and it was approved by the Complex 'Oswaldo Cruz University Hospital'/Pernambuco State University Cardiology Emergency Service 'Prof. Luiz Tavares' (HUOC/PROCAPE), according to the Expert Opinion No. 2.315.612.

\section{Results}

This study was carried out at 5 municipal public schools, which operated mostly in the 3 working shifts (morning, afternoon, and night), having from 150 to 200 students, and they provided Preschool Education, Elementary School, High School, and Youth and Adult Education, with an average of 30 to 40 students per class.

As for the teaching and living spaces, equipment, and activities available, we observed that most of the facilities had a library, but there were no laboratory, sports court, or auditorium. All schools had TV, but not all of them had other multimedia equipment.
Regarding the activities practised, besides traditional classes, the schools included in this study did not offer theater, music, or sports classes. Only 2 facilities provided capoeira and dance classes. Most schools were interconnected to the local community, but the same could not be said concerning the interconnection to universities, nongovernmental organizations (NGOs), and health programs.

The study participants consisted of 9 managers, i.e. 6 principals and 3 coordinators, most of them with graduate education and more than 15 years of experience in the function. There were 19 respondent teachers, most of them with graduate education and more than 10 years of teaching experience; they were teaching Portuguese, Mathematics, History, and Science, among other subjects.

Considering the managers' evaluation, the majority $(55.6 \%)$ stated that the school had sex education in its curriculum and that it is interconnected to the subjects Natural Science and Physical Education (55.6\%). For the subjects Portuguese, Mathematics, History, Geography, and Arts, most managers denied the existence of sex education (all had a percentage greater than $50.0 \%$ ). They also reported that sex education is not provided in informal activities (66.7\%). Regarding the themes worked on, the most frequently cited was body as the matrix of sexuality (77.8\%), followed by gender relations and STD prevention (both with 66.7\%). In addition, most managers stated that teachers receive guidance for dealing with sex education (66.7\%). Among the difficulties reported in sex education, managers highlighted the lack of dialogue with families (44.4\%). Table 1

When asked about suggestions for promoting sex education at school and minimizing the difficulties reported, managers said: 
To acquire support materials (anatomical models, videos, etc.).

More projects related to the theme.

To organize actions and seek support from the department of education.

Table 1. Managers' view about sex education at school. Recife, 2017.

\begin{tabular}{|c|c|c|c|c|}
\hline \multirow{3}{*}{ Assertions evaluated } & \multicolumn{4}{|c|}{ Answers } \\
\hline & \multicolumn{2}{|c|}{ Yes } & \multicolumn{2}{|c|}{ No } \\
\hline & $n$ & $\%$ & $\mathrm{n}$ & $\%$ \\
\hline $\begin{array}{l}\text { The school has sex education } \\
\text { in its curriculum }\end{array}$ & 5 & 55.6 & 4 & 44.4 \\
\hline $\begin{array}{l}\text { Teachers receive training for } \\
\text { sex education }\end{array}$ & 6 & 66.7 & 3 & 33.3 \\
\hline \multicolumn{5}{|c|}{ Sex education as a cross-sectional theme in the subjects } \\
\hline Portuguese & -- & & 9 & 100.0 \\
\hline Mathematics & 2 & 22.2 & 7 & 77.8 \\
\hline Natural Science & 5 & 55.6 & 4 & 44.4 \\
\hline History & 1 & 11.1 & 8 & 88.9 \\
\hline Geography & 1 & 11.1 & 8 & 88.9 \\
\hline Arts & 1 & 11.1 & 8 & 88.9 \\
\hline $\begin{array}{l}\text { Sex education in informal } \\
\text { activities }\end{array}$ & 3 & 33.3 & 6 & 66.7 \\
\hline \multicolumn{5}{|c|}{ Themes addressed in sex education } \\
\hline Body as the matrix of sexuality & 7 & 77.8 & 2 & 22.2 \\
\hline Gender relations & 6 & 66.7 & 3 & 33.3 \\
\hline STD prevention & 6 & 66.7 & 3 & 33.3 \\
\hline \multicolumn{5}{|c|}{ Difficulties related to sex education } \\
\hline Lack of dialogue with families & 4 & 44.4 & 5 & 55.7 \\
\hline $\begin{array}{l}\text { 'Gender and sexuality ideas of } \\
\text { teachers and students' }\end{array}$ & 1 & 11.1 & 8 & 88.9 \\
\hline $\begin{array}{l}\text { 'Lack of professionals qualified } \\
\text { to address the theme' }\end{array}$ & 1 & 11.1 & 8 & 88.9 \\
\hline There is no difficulty & 3 & 33.3 & 6 & 66.7 \\
\hline
\end{tabular}

Source: Prepared by the authors.
The survey of teachers' view about sex education at school showed that most teachers affirmed the existence of sex education as a formal content in grades equivalent to the period from 6 to 9 years of school education (83.3\%), mainly in the subject Science (62.5\%). As an informal activity, according to teachers, the theme sexuality is not addressed by them (78.9\%). Table 2

Table 2. Teachers' view about sexuality at school. Recife, 2017.

\begin{tabular}{c|c|c|c|c|c} 
Assertions evaluated & N & $\%$ & & Cl & $\begin{array}{c}P \\
\text { value }^{1}\end{array}$
\end{tabular}

Sex education exists as a formal content in the grades

\begin{tabular}{l|c|c|c|c|}
\hline $1^{\text {st }}$ to $5^{\text {th }}$ year & 1 & 5.6 & $1.0-25.8$ & $<0.001$ \\
\hline $6^{\text {th }}$ to $9^{\text {th }}$ year & 15 & 83.3 & $60.1-94.2$ &
\end{tabular}

Sex education exists as a content in the subjects

\begin{tabular}{|l|c|c|c|}
\hline Science & 15 & 62.5 & $42.7-78.8$ \\
\hline Physical Education & 4 & 16.7 & $6.9-35.8$ \\
\hline Geography & 2 & 8.2 & $2.3-25.8$ \\
\hline Portuguese & 1 & 4.2 & $0.7-20.2$ \\
\hline History & 1 & 4.2 & $0.7-20.2$ \\
\hline Art & 1 & 4.2 & $0.7-20.2$ \\
\hline
\end{tabular}

Sex education exists as a content in the subjects

\begin{tabular}{|l|c|c|c|c|}
\hline Yes & 4 & 21.1 & $8.5-43.3$ & 0.012 \\
\hline No & 15 & 78.9 & $56.7-91.5$ & \\
\hline
\end{tabular}

Themes addressed in sex education

\begin{tabular}{l|r|r|r|}
$\begin{array}{l}\text { Body as the matrix of } \\
\text { sexuality }\end{array}$ & 13 & 32.5 & $20.1-48.0$ \\
\hline \begin{tabular}{l} 
Gender relations \\
\hline STD prevention
\end{tabular} & 12 & 30.0 & $18.1-45.4$ \\
\hline
\end{tabular}

Received training for sex education

\begin{tabular}{|c|c|c|c|c|}
\hline Yes & 5 & 26.3 & $11.8-48.8$ & 0.039 \\
\hline No & 14 & 73.7 & $51.2-88.2$ & \\
\hline
\end{tabular}

Difficulties related to sex education at school

Infrastructure

$3 \quad 21.8 \quad 7.6-47.6$

Ignorance and prejudice

rooted in the culture

\begin{tabular}{l|l|l|}
1 & 7.1 & $1.3-31.5$
\end{tabular}

Students themselves are

ashamed about the theme
0.839 


\begin{tabular}{|c|c|c|c|c|}
\hline Assertions evaluated & $\mathbf{N}$ & $\%$ & $\mathrm{Cl}$ & $\begin{array}{c}P \\
\text { value }^{1}\end{array}$ \\
\hline \multicolumn{5}{|c|}{ Difficulties related to sex education at school } \\
\hline $\begin{array}{l}\text { Disinterest in municipal } \\
\text { management }\end{array}$ & 1 & 7.1 & $1.3-31.5$ & \\
\hline Teachers' training & 1 & 7.1 & $1.3-31.5$ & \\
\hline $\begin{array}{l}\text { Lack of projects involving } \\
\text { the theme }\end{array}$ & 1 & 7.1 & $1.3-31.5$ & \\
\hline None & 2 & 14.3 & 4.0-39.9 & \\
\hline Did not inform & 1 & 7.1 & $1.3-31.5$ & \\
\hline
\end{tabular}

The contents body as the matrix of sexuality, gender relations, and STD prevention are related to sexuality as a theme, they are mentioned with a similar frequency in the teachers' group $(32.5 \%$, $30.0 \%$, and $37.5 \%$ ) respectively.

As for guidance and training for sex education, most teachers said they did not receive such information (73.7\%) and that infrastructure is the main complicating factor in this regard (21.8\%). The proportion-comparison test was significant in all factors evaluated, except for themes addressed in sex education ( $p=0.839)$, indicating homoge-

Table 3. Distribution of contents worked on in the subjects. Recife, 2017.

Themes in sex education

\begin{tabular}{|c|c|c|c|}
\hline \multicolumn{4}{|c|}{ Answers } \\
\hline & & & \\
\hline $\mathrm{n}$ & $\%$ & $\mathrm{n}$ & $\%$ \\
\hline
\end{tabular}

The changes in men and women's body at the various life phases, from a comprehensive

A body perspective, involving emotions, feelings, and sensations related to well-being and the pleasure in self-care The mechanisms of conception, pregnancy, and childbirth, and the existence of contraceptive methods

C Changes due to puberty: maturation of sexual and reproductive functions

Emergence of secondary sexual features, variation in age at which puberty begins; changes due to accelerated physical growth

E Respect for one's own body and the other's body

F Respect for colleagues with a different physical and emotional development

G Strengthening self-esteem

$\mathrm{H}$ Serenity in relation to sexuality

Diversity of men and women's behavior depending on the time and the place they live in

J Relativity of ideas traditionally associated with men and women

$\mathrm{K}$ Respect for the other sex, represented by people with whom one interacts

$\mathrm{L}$ Respect for the many and varied expressions of women and men

M Knowing the existence of STDs

$\mathrm{N}$ Understanding the ways of preventing and transmitting AIDS

Comparison between the forms of contact that lead to contagion and those that do not involve risks

P Knowledge and adoption of procedures needed in accident or injury situations enabling blood contact

Q Repudiation of discrimination against patients with HIV and AIDS

$\mathrm{R} \quad$ Respect and solidarity towards patients with HIV or AIDS \begin{tabular}{l|l|l|l}
47.4 & 10 & 52.6 & 0.819
\end{tabular}

\begin{tabular}{|l|l|l|l|}
\hline 42.1 & 11 & 57.9 & 0.491 \\
\hline
\end{tabular}

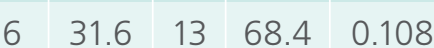

$\begin{array}{lllll}4 & 21.1 & 15 & 78.9 & 0.012\end{array}$

\begin{tabular}{l|l|l|l|l}
12 & 63.2 & 7 & 36.8 & 0.251
\end{tabular}

\begin{tabular}{l|l|l|l|l}
11 & 57.9 & 8 & 42.1 & 0.491
\end{tabular}

\begin{tabular}{l|l|l|l|l|}
11 & 57.9 & 8 & 42.1 & 0.491
\end{tabular}

\begin{tabular}{l|l|l|l|l}
4 & 21.1 & 15 & 78.9 & 0.012
\end{tabular}

$\begin{array}{lllll}12 & 63.2 & 7 & 36.8 & 0.251\end{array}$

\begin{tabular}{lllll|l}
6 & 31.6 & 13 & 68.4 & 0.251
\end{tabular}

\begin{tabular}{l|l|l|l|l}
13 & 68.4 & 6 & 31.6 & 0.108
\end{tabular}

\begin{tabular}{l|l|l|l|l|}
11 & 57.9 & 8 & 42.1 & 0.491 \\
\hline
\end{tabular}

\begin{tabular}{l|l|l|l|l|}
8 & 42.1 & 11 & 57.9 & 0.491
\end{tabular}

$\begin{array}{lllll}7 & 36.8 & 12 & 63.2 & 0.251\end{array}$

\begin{tabular}{l|l|l|l|l}
6 & 31.6 & 13 & 68.4 & 0.108
\end{tabular}

\begin{tabular}{|l|l|l|l|l|}
\hline 1 & 5.3 & 18 & 94.7 & $<0.001$ \\
\hline 6 & 31.6 & 13 & 68.4 & 0.108 \\
\hline 6 & 31.6 & 13 & 68.4 & 0.108 \\
\hline
\end{tabular}

1: P value of the chi-square test for proportion comparison.Source: Prepared by the authors. 
Table 4. Distribution of teenagers according sex education topics. Recife, 2017.

\begin{tabular}{|c|c|c|c|c|c|c|c|}
\hline \multirow{2}{*}{ Variables } & \multicolumn{3}{|c|}{ Yes } & \multicolumn{3}{|c|}{ No } & \multirow{2}{*}{$P$ value } \\
\hline & $\mathrm{n}$ & $\%$ & $\mathrm{Cl}$ & $n$ & $\%$ & $\mathrm{Cl}$ & \\
\hline There is sex education at school & 142 & 84.5 & $78.3-89.2$ & 26 & 15.5 & $10.8-21.7$ & $<0.001$ \\
\hline Subject related to sex education & 77 & 54.6 & $46.4-62.6$ & 64 & 45.4 & $37.4-53.6$ & 0.274 \\
\hline Sex education in informal activities & 44 & 31.2 & $24.1-39.3$ & 97 & 68.8 & $60.7-75.9$ & $<0.001$ \\
\hline \multicolumn{8}{|l|}{ Contents related to sex education } \\
\hline Anatomy and puberty & 117 & 72.7 & $65.3-79.0$ & 44 & 27.3 & $21.0-34.7$ & $<0.001$ \\
\hline Ways of expressing sexuality & 83 & 51.6 & $43.9-59.2$ & 78 & 48.4 & $40.8-56.1$ & 0.694 \\
\hline Gender relations & 77 & 47.8 & $40.2-55.6$ & 84 & 52.2 & $44.5-60.0$ & 0.581 \\
\hline STDs & 130 & 80.7 & $74.0-86.1$ & 31 & 19.3 & $13.9-26.0$ & $<0.001$ \\
\hline
\end{tabular}

neity in the frequency of approach to all themes described.

Regarding the distribution of sex education contents and teachers' view about the approach in the subjects they are responsible for, the most frequently mentioned contents were: respect for the other sex, represented by people with whom one interacts (68.4\%), respect for one's own body and the other's body (63.2\%), and diversity of men and women's behavior according to the time and place where they live in (63.2\%). Table 3

The less prominent themes were: knowledge and adoption of procedures needed in accident or injury situations enabling blood contact (5.3\%); serenity in relation to sexuality and emergence of secondary sexual features, variation in age at which puberty begins; changes due to accelerated physical growth (all of them with $21.1 \%$ ).

The proportion-comparison test was significant in the three contents with lower prevalence in the classroom $(p<0.05)$, indicating that, in fact, these themes are strongly overlooked by the teachers assessed. The other themes are worked on by a number of teachers statistically equivalent to those who do not work on these themes.

As for the adolescent interviewees, $40.5 \%$ were men and $59.5 \%$ were women, the majority were between 10 and 14 years old, and had a family income between 1 and 5 minimum wages. At the time the study was conducted, 1 minimum wage corresponded to R\$937 (about US\$287).

Considering the profile of adolescent students according to sexual and reproductive behavior, the majority reported to have already had their first sexual intercourse, aged between 10 and 14 years, as well as to use condoms and they denied STDs and pregnancy.

Focusing on the distribution of teenagers according to information on the sexuality approach, most of the students stated there is sex education at school as a formal content in the subjects (84.5\%), but they denied the existence of informal activities addressing sex education (68.8\%). Table 4

Regarding the sex education themes known to students, STDs, anatomy, and puberty were the most cited contents $(80.7 \%$ and $72.7 \%$, respectively). The ways of expressing sexuality and gender relations were the themes that teenagers reported to have less knowledge about (51.6\% and $47.8 \%$, respectively).

\section{Discussion}

Working on sex education at school is still a challenge to face from the perspective of managers and teachers. Sexuality in the educational space 
'invades' the school through the students' attitudes in the classroom and the social interaction between them. The school, willingly or not, experiences situations related to sexuality with which it always intervenes. Either in the classroom, on an everyday basis, when it prohibits or allows certain manifestations and not others or when it chooses to inform parents of their child's manifestations, the school is always transmitting values, more or less strict, depending on the professionals involved at that moment.

Sexuality, regarded as a social, historical, and cultural construction, represents a need that should be discussed at school, a privileged space for pedagogical approach to this contemporary educational challenge [8]. The proposal of pedagogical work on sexual diversity is inserting it in the various subjects of the curriculum through the contents listed in the Brazilian Curricular Guidelines of Elementary Education. From this perspective, the class, race/ethnicity, gender, and sexual diversity references are considered. The challenge is to provide teachers with resources on a theoretical basis through continuing education and the production of teaching support materials.

The school, as a formal educational institution, anchored in legislation, has guidelines of its own, a faculty defined for the knowledge areas, and it also has all the legal and scientific foundations for a more effective discussion concerning sexuality, but it often does not do this because it is bound to beliefs, moral values, and customs established historically and culturally in our country, contributing to the segregation, prejudice, and discrimination of so many individuals that do not fit in social standards and socially accepted behaviors [9].

Sexuality as a theme must be addressed at school and it should be included in the pedagogical political project of these educational institutions. In the PCNs [10], sex education, named as Sexual Guidance for Elementary Education, should consider sexuality as something inherent to life and health, expressed by a human being, from birth to death. Sexuality-related contents must necessarily be worked on and should always be covered, in order to guarantee basic information and discussion about sexuality. These contents allow addressing the various issues, which vary according to the age group, regional culture, and contemporary events conveyed by the media or experienced by a certain community. The challenge is providing these aspects, regarded as key, with visibility. Working on sexual guidance implies thinking of and opposing to the sexuality-related stereotypes of gender, race, nationality, culture, and social class.

Although managers argue that teachers are capable of working from a sex education perspective, teachers claim to need more training in this regard. We cannot ignore how difficult it has been for teachers to work on sex education at school [11]. Teachers sometimes do not know how to deal with issues and experiences that arise in everyday school life and ignore themes of extreme relevance, not knowing how to approach them, being afraid of the reaction and lack of support from the family, not knowing the most appropriate ways to seek information and embrace different positions that may arise among students. Perhaps the greatest challenge facing the teacher who deals with issues related to gender and sexuality is precisely the need to break with paradigms of his own, to enter a continuous process of deconstruction and reconstruction of socially-built values (many of them historically overcome and modified).

The first issue on gender and sexuality with which the teacher has to deal at school refers to the conflict that may exist between his role as a professional who should ensure respect and understanding with regard to the diversity of values and beliefs [11].

As provided for by the PCNs [10], one of the aspects associated with sex education quality is the training level of a teacher or an education professio- 
nal who is responsible for this task. It is important that the teacher seeks a theoretical basis on the issues of sexual guidance. Because this is a multidisciplinary theme, it involves contributions from various knowledge areas, such as Education, History, Sociology, Anthropology, Psychology, Psychoanalysis, Economics, etc. It is also worth constructing a continued participatory methodology, which involves dealing with group dynamics, application of awareness-raising techniques, and facilitation of debates.

Teachers lack information, specialized training, and knowledge on how to address sexual guidance with children and teenagers at each specific development stage [12]. So, when faced with these situations, they think that students need a lot more than they can offer. It is worth noticing that almost all teachers work on sex education with their students, even when they do not realize it. A teacher should be aware of his values, beliefs, opinions, and feelings in relation to sexuality and that this is a major element for him to take an ethical attitude towards the students.

The teacher does not have to be an expert in sex education, but only a professional properly informed about human sexuality who thinks of it, being able to create appropriate pedagogical contexts and select strategies for information, reflection, and debate of ideas, as well as to recycle and update his knowledge in order to teach how to think, becoming a mediator of knowledge [13].

Regarding managers, from a sex education perspective, there is a need to: raise awareness of the students' parents through meetings aimed at the deployment of sexual guidance projects; promote continuing education for educators, so that they can be provided with means and supported in the discussion about sexuality at school; monitor and promote actions related to sex education and seek to develop and participate in other actions and activities of projects related to the theme [12].
Managers and teachers agree that there must be infrastructure such as pedagogical support and appropriate teaching materials to provide educational actions with means. According to these professionals, the poor infrastructure of public schools affects education quality. The lack of computer rooms, laboratories, and sports spaces, besides the overcrowded classrooms, are problems that negatively affect students' learning. The strategy adopted by educators at school is usually the traditional methodology, i.e. a vertical teacher-student relationship, where content is approached and it is up to the student assimilating what has been said [14].

Thus, there is a need to minimize these difficulties by promoting the use of course materials that deepen and give rise to discussing the (social and particular) values associated with sexuality as a theme. Gathering a collection of materials at school (such as texts and course textbooks, videos, games, exercises, and dramatization proposals) is relevant for this work [10].

In addition to expository classes, we must seek teaching strategies that promote dialogue, selfknowledge, and interconnection between thinking, feeling, and acting, as well as create an environment of trust and reflection [15]. In this way, it is worth resorting to dramatization, group dynamics, drawing, modeling, and cut and paste. Contents about sexuality must be 'within the program,' i.e. contents addressing sexuality as proposed, organized, planned, and divided among teachers in each grade. In addition, there is an 'extraprogram,' in which any teacher, without prior planning, takes advantage of a fact that arises spontaneously for sex education.

Another aspect that worries managers and teachers is dialogue with families. They emphasize not feeling properly prepared to address this issue with family members and the latter sometimes do not accept the approach to sex education at school. However, it is emphasized that the family alone, in the current context, does not meet the need 
to educate children and teenagers for all human challenges, and such a responsibility is assigned to other institutions, such as the school, which complement the education process initiated by the family through work on a daily basis, with a view to promoting citizenship [9]. At least it should be this way, according to the current discourses in education circles. However, in the family context, education is based on human experiences, it is not systematized, discussed, and studied in the academic spheres and this often leaves individuals exposed to socioculturally constructed stigmata, beliefs, ideals and taboos.

Managers and teachers resent the lack of dialogue with family members about the students' sexuality and, at the same time, they are afraid of parents' criticism concerning the type of information on sexuality conveyed by the school to teenagers and also about the way this takes place. However, previously the idea was that families were against addressing this subject at school [16]. Nevertheless, it is noticed today that most parents ask for sexual guidance at school, since they recognize not only its importance for children and teenagers, but also the difficulty of talking openly about it in the family. It is also emphasized that, despite the major role played by the school concerning sexuality, it should not replace the dialogue and guidance on sexuality within the family unit.

Faced with these challenges, some authors suggest the collaboration of experts in initiatives for systematic guidance and training of teachers [17]. The development of these activities could, among other benefits, collaborate to provide teachers with greater confidence when addressing sexuality in face of the questions that may be asked by students. The authors explain that there should be teacher training, relying on the collaboration of experts in sexuality, in order to offer spaces for listening and advice/guidance for students and parents, as well as the dissemination among teachers of information on specialized services, e.g. for dealing with cases of sexual violence, harassment, and rape, both at school and within the family unit, besides other spaces, so that they can refer the young victims.

A key aspect refers to the assumption that sex education is a cross-sectional theme that must be worked on in all subjects of the school curriculum. Sex education goes far beyond biological concepts related to human reproduction. It is not restricted to systematic study within Natural Science. The school approach to sexuality should not be limited to the Biology or Physical Education teacher, it has to be present in all knowledge areas covered by Elementary Education [18]. Sexuality will take a new meaning in this space if the classroom dynamics is re-signified, too, becoming a space where opinions, uncertainties, and divergences are properly considered and discussed $[19,20]$.

Scholars in the field of sex education have pointed out the relevance that educational policies are broader and address the subjective, social, and cultural dimensions of sexuality, as well as the biological aspects of this phenomenon. As for this view about sexuality, some authors point out that this is a non-linear construction, crossed by various historical, social, and cultural conditions [21]. Sexuality is claimed to be something purely individual, private, and biological, instead of a sociocultural construct that leads to restrictive practices, which may interfere with the adoption or not of preventive behaviors.

One aspect highlighted by the study was the poor interconnection between the school and other institutions and social organizations that could contribute both to train teachers and provide them with support when working on sex education along with teenagers and family members. Higher Education institutions, as well as civil society organizations, can offer educational services through covenants and partnerships, in order to contribute to technical functions of public bodies in staff training, preparation of course material, and formulation of pedagogical guidelines [22]. 
When analyzing the teenagers' viewpoint, attention is drawn to the fact that they identify the school as a source of information with regard to sex education, however, they emphasize the contents related to bodily changes and STDs. By analyzing the sexual behavior profile of these adolescent students, it was found that many already had active sexual life before 15 years of age.

Sexual initiation may be claimed as a remarkable event in a teenager's life [23]. At the same time, as it allows entering a world of new discoveries, this can lead a teenager to a group of vulnerability to STDs and AIDS. This insertion can also result in the occurrence of pregnancy in adolescence, abortion, and other biological, socioeconomic, and psychological problems. So, the school and the family cannot avoid providing access to information that promotes a safe and healthy experience of a teenager's sexuality.

The Brazilian Act of Guidelines and Bases for National Education (Law No. 9,394/1996) included in the PCNs sex education as a cross-sectional theme, justified by demographic and epidemiological issues among adolescents, such as: increased number of pregnant women and infection with the human immunodeficiency virus (HIV) and other STDs. Guidelines on contents related to sexual guidance involve the body as the matrix of sexuality, STDs, and also gender relations [24].

However, this study revealed that the teenager participants did not know the meaning of gender or its relations and social implications, as it was not a 'subject' addressed in the classroom. Emphasizing once again that guidance on sexuality remains focused on biological issues.

Gender relations start from the view on the bodily and sexual differences, from a cultural perspective, which are created in society, about the ideas of what being a man or a woman means [25]. So, as a consequence, hierarchies and power relations emerge in each time, space, and social group. Gender may be seen as the process through which society classifies and assigns values and standards, thus constructing sexual differences and hierarchies, delimiting what the male and female roles might be.

Sexuality encompasses the dynamics permeating the reproductive boundaries, advancing through feelings of pleasure and satisfaction. Thus, according to some authors, sexuality as an aspect of cultural identity covers intimate desire regarding sex, revealing emotional involvement, desirable reproduction (or not), sexual guidance, sexual identity, eroticism, and gender [26]. These issues cannot be excluded from guidance on sexuality at school.

Therefore, the school is extremely significant to demystify differences, as well as it constitutes an instrument in the construction of values and attitudes that allow a rather critical and reflective adolescents' view on gender identities, so that the behaviors that reflect inequality, prejudice, and discrimination are not reproduced in society.

\section{Conclusion}

The results of this study indicate that sex education at public schools, from the perspective of managers, teachers, and adolescents, still has limitations and challenges to be faced with regard to the development of this theme as a cross-sectional content in Elementary Education.

The school infrastructure - with shortcomings related to living spaces and teaching scenarios, poor teacher vocational education, difficulty to dialogue with families, lack of interconnection to other educational and health institutions- contribute so that sex education remains as a theme discussed in traditional classes and biology-based classes in terms of teenagers' bodily changes and STDs.

The psychological, cultural, and relational aspects of healthy and safe sexuality still remain as knowledge gaps, identified by teenagers themselves, and this justifies the expansion of spaces for dialogue and embracement of human diversity at school. 


\section{References}

1. Lima FCA, Jesus FB, Martins CBG, Souza SPS, Matos KF. Experience and attitudes of teenagers facing sexuality. Mundo Saúde. [Internet]. 2013 [cited 2018 Sep 11]; 37: 385-393. Available from: http://bvsms.saude.gov.br/bvs/artigos/mundo saude/ experiencia atitudes adolescentes frente sexualidade.pdf.

2. Moraes SP, Vitalle MSS. Sexual and reproductive rights in adolescence. Rev Assoc Méd Bras. [Internet]. 2012 [cited 2018 Sep 11]; 58: 48-52. Available from: http://www.scielo.br/scielo. php?Script=sci arttext\&pid=S010442302012000100014\&lng= en\&nrm=iso.

3. Gonçalves RC, Faleiro JH, Malafaia G. Sexual education, family and school: challenges and impasses. Holos. [Internet]. 2013 [cited 2018 Sep 11]; 5: 251-263. Available from: http://www2. ifrn.edu.br/ojs/index.php/HOLOS/article/view/784.

4. Louro GL. Gender, sexuality and education: from political affinity to theoretical-methodological tensions. Educ Rev. [Internet]. 2007 [cited 2018 Sep 11]; 46: 201-218. Available from: http:// www.scielo.br/pdf/edur/n46/a08n46.

5. Aquino C, Martelli AC. Escola e educação sexual: uma relação necessária. IX Seminário ANPED Sul; 2012; Caxias do Sul, BR. Annals. Caxias do Sul (RS): Universidade de Caxias do Sul; 2012.

6. Dantas GCS. Educação sexual. [Internet]. 2012 [cited 2018 Sep 11]. Available from: https://brasilescola.uol.com.br/sexualidade/ educacao-sexual.htm.

7. Silva RM. Educação para a sexualidade no Ensino Fundamental: discursos e práticas de pais e professores. [Internet]. Brasília (DF): Universidade Católica de Brasília; 2015 [cited 2018 Sep 11]. Available from: https://bdtd.ucb.br:8443/jspui/ bitstream/123456789/799/1/Rosenilda\%20Moura\%20da\%20 Silva.pdf

8. Nogueira DM. Gênero e sexualidade na educação. I Simpósio sobre Estudos de Gênero e Políticas Públicas; 2010; Londrina, BR. Annals. Londrina (PR): Universidade Estadual de Londrina; 2010.

9. Peixoto R. Orientação sexual: entre a família e a escola, a quem compete educar? V Seminário Internacional Enlaçando Sexualidades; 2017; Salvador, BR. Annals. Salvador: Universidade do Estado da Bahia; 2017.

10. Brasil. Parâmetros Curriculares Nacionais: orientação sexual. Brasília (DF): Secretaria de Educação Fundamental; 1997.

11. Pessôa LC, Pereira R, Toledo R. Ensinar gênero e sexualidade na escola: desafios para a formação de professores. Revista de Estudos Aplicados em Educação. [Internet]. 2017 [cited 2018 Sep 11]; 2: 18-32. Available from: http://seer.uscs.edu.br/index. php/revista estudos aplicados/article/view/4729/2234
12. Amaral CJB, Oliveira EB. Orientação sexual na educação infantil como estratégia de gestão escolar: manifestações da sexualidade - um desafio para pais e educadores nas escolas públicas municipais de Jequié-BA. III Seminário Internacional Enlaçando Sexualidades; 2013; Salvador, BR. Annals. Salvador: Universidade do Estado da Bahia; 2013.

13. Moizés JS, Bueno SMV. Understanding sexuality and sex in schools according to primary education teachers. Rev Esc Enferm USP. [Internet]. 2010 [cited 2018 Sep 11]; 44: 205-212. Available from: $\quad$ http://www.scielo.br/pdf/reeusp/v44n1/en a29v44n1. pdf.

14. Monteiro JS, Silva DP. The influence of the pertaining to school structure in the teach-learning process: an analysis based on the experiences of the period of training supervised in Geography. Geografia Ensino \& Pesquisa. [Internet]. 2015 [cited 2018 Sep 11]; 19: 19-28. Available from: https://periodicos.ufsm.br/ geografia/article/view/14315/pdf.

15. Figueiró MND. Sexual education: how to teach in the school environment. Revista Linhas. [Internet]. 2006 [cited 2018 Sep 11]; 7: 1-21. Available from: http://www.periodicos.udesc.br/ index.php/linhas/article/view/1323/1132.

16. Savegnago SO, Arpini DM. Escola, família e sexualidade: diálogos possíveis? IV Seminário Internacional Enlaçando Sexualidades; 2015; Salvador, BR. Annals. Salvador: Universidade do Estado da Bahia; 2015.

17. Abramovay M, Castro MG, Silva LB. Juventude e sexualidade. Brasília (DF): Unesco; 2004.

18. Novak E. Dificuldades enfrentadas pelos professores ao trabalhar educação sexual com adolescentes. Medianeira (PR): Universidade Tecnológica Federal do Paraná; 2013.

19. Lira A, Jofili Z. O tema transversal orientação sexual nos PCN e a atitude dos professores: convergentes ou divergente? REMPEC: Ensino, Saúde e Ambiente. 2010; 3: 22-41.

20. Silva Junior JA. Sexualidade e educação: um diálogo necessário. Lugares de Educação. [Internet]. 2011 [cited 2018 Sep 11]; 1: 218-238. Available from: http://www.periodicos.ufpb.br/ojs/ index.php/rle/article/view/10965/7270.

21. Vieira PM, Matsukura TS. Frameworks of sexual education in schools: conceptions and practices of public middle school teachers. Rev Bras Educ. [Internet]. 2017 [cited 2018 Sep 11]; 22: 453-474. Available from: http://www.scielo.br/pdf/rbedu/ v22n69/1413-2478-rbedu-22-69-0453.pdf. 
22. Ghanem E. The NGOs and governmental responsibility for basic school in Brazil. Pro-Posições. [Internet]. 2012 [cited 2018 Sep 11]; 23: 51-65. Available from: http://www.scielo.br/pdf/pp/ v23n2/a05v23n2.pdf.

23. Silva $A S N$, Silva BLCN, Silva Júnior $A F I$, Silva $M C F$, Guerreiro JF, Sousa ASCA. Onset of sexual intercourse among adolescent students: a cross-sectional study of sexual risk behavior in Abaetetuba, Pará State, Brazil. Revista Pan-Amazônica de Saúde. [Internet]. 2015 [cited 2018 Sep 11]; 6: 27-34. Available from: http://scielo.iec.gov.br/pdf/rpas/v6n3/v6n3a04.pdf.

24. Lima LJS. A Estratégia Saúde da Família e a educação sexual: um estudo em unidade de saúde da família. Porto Velho: Universidade Federal de Rondônia; 2014.

25. Guimarães LC. Relações de gênero e sexualidade. São Luís: Universidade Federal do Maranhão; 2010.

26. Lima E, Almeida GB. Educação sexual e prática pedagógica. Abordagens interdisciplinares sobre história da sexualidade. Recife: Universidade Católica de Pernambuco; 2010.

Publish in International Archives of Medicine

International Archives of Medicine is an open access journal publishing articles encompassing all aspects of medical science and clinical practice. IAM is considered a megajournal with independent sections on all areas of medicine. IAM is a really international journal with authors and board members from all around the world. The journal is widely indexed and classified Q2 in category Medicine. 